\title{
Study of the association between serum zinc concentration in pregnant women and preterm birth
}

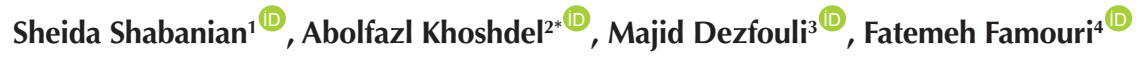 \\ 'Department of Gynecology and Obstetrics, Shahrekord University of Medical Sciences, Shahrekord, Iran \\ ${ }^{2}$ Clinical Biochemistry Research Center, Shahrekord University of Medical Sciences, Shahrekord, Iran \\ ${ }^{3}$ Shahrekord University of Medical Sciences, Shahrekord, Iran \\ ${ }^{4}$ Department of Gasterology, Isfahan University of Medical Sciences, Isfahan, Iran
}

*Corresponding Author: Abolfazl Khoshdel, Clinical Biochemistry Research Center, Shahrekord University of Medical Sciences, Rahmatiyeh, Shahrekord, Iran, Tel: +98 383 3338891, Fax: +98 383 2249506, Email: nikakhosh@gmail.com

\begin{abstract}
Background and aims: Preterm birth can cause high morbidity and mortality in women. Previous evidence has confirmed the association between zinc $(\mathrm{Zn})$ deficiency in $\mathrm{x}$ women and some pregnancy complications. This study investigated the association between serum $\mathrm{Zn}$ concentration in pregnant women and preterm birth.

Methods: This case-control study focused on evaluating 76 pregnant women with preterm birth (case group) and 62 pregnant women with term birth (control group) and was conducted in the obstetrics ward of Hajar hospital, Shahrekord, Iran in 2014. The Zn level was measured by spectrophotometry and data were analyzed by SPSS, version 15 .

Results: The prevalence of $\mathrm{Zn}$ deficiency was $95.6 \%$. The mean of serum $\mathrm{Zn}$ concentration was $39.62 \pm 11.83$ and $59.81 \pm 8.8$ in the preterm and term delivery groups, respectively $(P<0.001)$. Similarly, the mean of serum $Z n$ concentrations was $43.06 \pm 15.6$ and $50.46 \pm 13.8$ in women with and without the rupture of pregnancy membranes, respectively $(P=0.01)$. Based on the findings, the serum $\mathrm{Zn}$ concentration was not significantly associated with parity $(P=0.634)$.

Conclusion: Although a decrease in the serum $\mathrm{Zn}$ concentration could lead to premature rupture of membranes during pregnancy and preterm birth, it could not be considered as the main factor for preterm birth. In addition, Zn deficiency was highly prevalent in pregnant women. Therefore, nutritional interventions should be performed to prevent complications due to the deficiency of micronutrients such as $\mathrm{Zn}$ so that to increase health maintenance in mothers and children.

Keywords: Serum, Zinc, Pregnant women, Preterm birth
\end{abstract}

Received: 18 August 2019, Accepted: 10 November 2020, ePublished: 29 September 2021

\section{Introduction}

Preterm birth refers to delivery before 37 completed weeks (259 days) of gestation and continues to be one of the major health and prenatal problems (1-3). In 2010, $11.1 \%$ of all (14.9 million) live births were estimated to be preterm (4). Preterm birth results in stupendous costs for communities, namely, 26 billion dollars a year in the United States (5). The risk factors of preterm birth include socioeconomic status, age, gender, placental and uterine problems, chronic underlying disease, history of stillbirth, preterm delivery, genetics, bacteriuria, history of alcohol and drug abuse, smoking, nulliparity, multiple pregnancies, low maternal body mass index (BMI), stress and heavy physical work (6-11). Further, nutrition and supplement intake are considered important factors for the prevention of preterm birth (12). Zinc ( $\mathrm{Zn})$ is a rare and essential element for the body, as well as an importantly required mineral for health maintenance in humans. Decreases in the serum $\mathrm{Zn}$ level could cause preterm delivery, stillbirth, low birth weight, growth restriction, congenital anomalies, and genetic problems $(12,13)$ This decrease is rapidly and progressively pronounced in pregnancy, challenging women's capacity to metabolically adjust with certain conditions of pregnancy (14). Complications due to $\mathrm{Zn}$ deficiency lead to half million mortalities in women and children, particularly in developing countries. The need for $\mathrm{Zn}$, which is intensified in pregnancy and pregnant women, could develop adverse complications of pregnancy due to $\mathrm{Zn}$ deficiency and their fetuses may have improper growth (4).

Studies have indicated that $\mathrm{Zn}$ supplementation could help in decreasing the complications of labour and reinforcing infants' immunity system (15) although the findings of another study indicated an association between $\mathrm{Zn}$ deficiency and preterm birth (16). Some studies demonstrated that $\mathrm{Zn}$ supplements intake in pregnancy has no notable contribution to preventing preterm birth with an extremely small effect. Based on the findings of human studies, the low level of $\mathrm{Zn}$ has no association with the weight at birth and head circumference. However, a similar study reported the relationship between $\mathrm{Zn}$ deficiency and a decrease in head circumference, low 
weight at birth, delivery of small-for-gestational-age neonate, and prenatal weak results (17).

Regarding the significance of preterm birth for health in women and children, and numerous potential problems due to $\mathrm{Zn}$ deficiency, the present study evaluated the association between serum $\mathrm{Zn}$ concentrations in pregnant women and preterm birth in Hajar Hospital in Shahrekord, southwest Iran.

\section{Materials and Methods}

Based on convenience sampling, 76 pregnant women with preterm birth (case group) and 62 pregnant women with term birth (control group) were investigated in this case-control study. These women had been referring to the obstetrics ward of Hajar hospital, Shahrekord, Iran during 2014. The sample size was calculated based on a $95 \%$ confidence interval and a power of $80 \%$ to find a difference equal to $50 \%$ of standard deviation in the mean of the serum $\mathrm{Zn}$ concentration between the two groups. The sample size was obtained as 63 patients in each group. Before enrollment, written consent was obtained from the women, and research ethics was followed as much as possible throughout the study. Within an approximately three-week interval, an initial description was obtained from all women. The patients were enrolled, and $5 \mathrm{~mL}$ serum was obtained from them using a freshly inserted branula.

The serum samples were stored after obtaining a complementary description and further confirming the enrollment of each patient. The age range of 20-40 years, gestational age under 37 weeks, and single pregnancy were considered as the inclusion criteria for the control group. The women of 20-40 years with a gestational age of 20-37 weeks, confirmed onset of preterm labour, and completed labour were assigned to the treatment group. On the other hand, the exclusion criteria consisted of a history of premature labour, uterine anomalies, smoking, history of urinary tract infection, previous ultrasound diagnosis of the short cervix $(<15 \mathrm{~mm})$, and low pre-pregnancy weight (BMI <20). Other exclusion criteria were low socioeconomic status, history of any infectious diseases, gastrointestinal diseases, acrodermatitis enteropathica, kidney disease, diabetes mellitus, rheumatologic diseases such as lupus and scleroderma, alcoholism or addiction to opioids, severe burns, and undergoing surgery during pregnancy. Moreover, the use of $\mathrm{Zn}$ supplements and the onset of abnormal contraction due to trauma and labourinducing medications, abnormal membrane rupture in pregnancy such as manipulation and trauma, multiple pregnancies, and medical termination of pregnancy are other exclusion criteria.

The required data were registered in a questionnaire by the researcher. The serum samples were obtained from the participants under study in the tubes for measurement. The validity and reliability of the instrument for data collection were derived from similar previous studies and studies on the measurement of the serum $\mathrm{Zn}$ concentration, and the best available choices were used in the present study (5).

The process of labour initiation and the delivery process were briefly recorded in a questionnaire, and after rechecking the exclusion and inclusion criteria and completing the required data, the samples were quickly transferred to the hospital laboratory to obtain the serum. Then, the serum samples were collected and refrigerated at $-20^{\circ} \mathrm{C}$. Shorter than one hour after taking out the serum samples from the refrigerator, they were centrifuged for 20 minutes at $3000 \mathrm{rpm}$, and the separated serum was poured into acid-rinsed tubes. The serum $\mathrm{Zn}$ concentration of lower than $70 \mu \mathrm{g} / \mathrm{dL}$ was considered to be $\mathrm{Zn}$ deficiency in pregnancy (18).

The serum $\mathrm{Zn}$ concentration was measured by the atomic method, and the collected data were stabilized as well. Data were analyzed by the statistical package for the Social Sciences (SPSS, version 15) using the independent $t$ test and the Kruskal-Wallis test.

\section{Results}

In general, 76 women aged $20-40$ years with a gestational age of 20-37 weeks with preterm delivery were defined as the treatment group and 62 women aged 20-40 years with the gestational age of over 37 weeks with term delivery were considered as the control group. The mean of serum Zn concentration was $39.62 \pm 11.83$ and $59.81 \pm 8.8$ in the preterm delivery and the delivery groups, respectively. There was a significant difference between the two groups $(P<0.001$; Table 1, Figure 1). The mean of the serum $\mathrm{Zn}$ concentration in women with rupture of pregnancy membranes was $43.06 \pm 15.6$ while it was $50.46 \pm 13.8$ in women without rupture of pregnancy membranes $(P=0.01)$. Eventually, the serum $\mathrm{Zn}$ concentration was not significantly associated with parity $(P=0.634$, Table 1$)$.

\section{Discussion}

In the present study, decreases in the serum $\mathrm{Zn}$ concentration and lower gestational age were not associated in either of the studied groups, but a further decrease in the serum $\mathrm{Zn}$ concentration was related to an increase in preterm birth and premature rupture of pregnancy membranes. Decreases in the serum $\mathrm{Zn}$ level

Table 1. The serum zinc concentration based on preterm delivery, rupture of pregnancy membranes and parity

\begin{tabular}{lccc}
\hline Variable & Group & Mean \pm SD & P Value \\
\hline Delivery & Term & $59.81 \pm 8.8$ & \\
& Preterm & $39.62 \pm 11.83$ & $<0.001$ \\
Rupture of pregnancy membranes & Yes & $43.06 \pm 15.69$ & \\
& No & $50.46 \pm 13.83$ & 0.011 \\
& 0 & $50.33 \pm 15.05$ & \\
Parity & 1 & $46.45 \pm 13.5$ & \\
& 2 & $49.73 \pm 14.99$ & 0.634 \\
& $\geq 3$ & $47.11 \pm 15.05$ & \\
\hline
\end{tabular}

Note. SD: Standard deviation. 


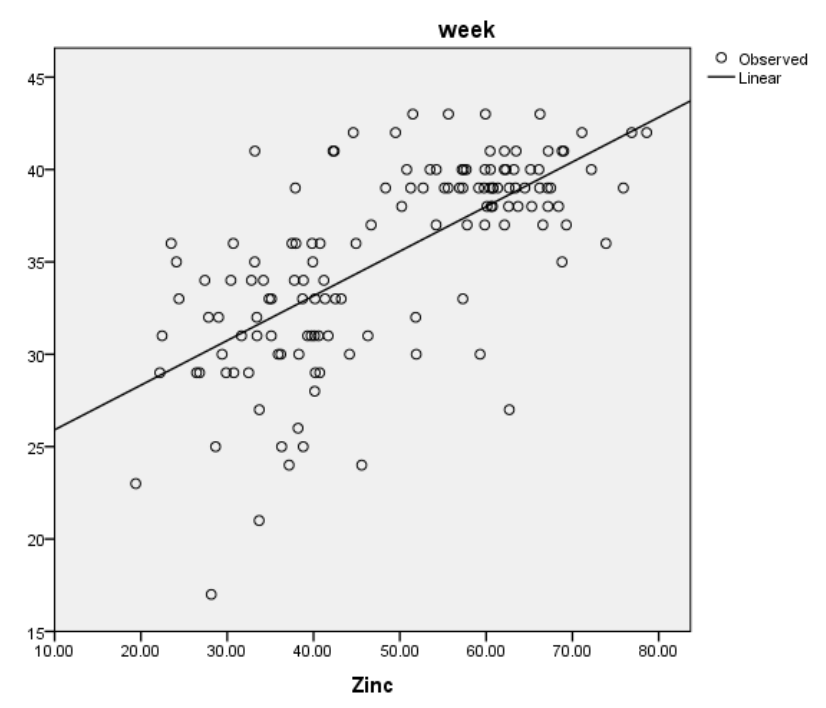

Figure 1. Association between serum zinc concentration and gestational age in the studied women.

could be considered as a predictor rather than a preterm delivery.

In a study by Boskabadi et al, the serum Zn level was measured by spectrophotometry, and the results revealed that $\mathrm{Zn}$ deficiency was high in both groups under study. Moreover, the mean serum $\mathrm{Zn}$ level in women with labour of shorter than 37 weeks of gestation was significantly lower, and serum $\mathrm{Zn}$ level was lower in preterm births (19).

Likewise, Nossier et al demonstrated that stillbirth and preterm delivery were lower in women taking $\mathrm{Zn}$ supplement compared to those receiving a placebo (15). However, the results of a study of serum $\mathrm{Zn}$ and copper concentrations and premature rupture of pregnancy membranes and preterm birth represented no separate contribution of serum $\mathrm{Zn}$ and copper concentrations to premature rupture of pregnancy membranes (20). Shah and Sachdev concluded that the routine intake of $\mathrm{Zn}$ supplements by women could not enhance pregnancy outcomes (21). The inconsistency in the findings of different studies could be explained by failing to control for other nutritional factors, history of preterm birth, smoking, race, multiple pregnancies, infections, lifestyle, and the like that may have played a role in preterm birth in some studies. In addition, decreased serum $\mathrm{Zn}$ concentrations in pregnant women could result from the reasons that cause preterm delivery.

On the other hand, the serum $\mathrm{Zn}$ concentration is a highly sensitive variable for measurement. The findings regarding the measurement of the serum $\mathrm{Zn}$ concentration are mainly comparative rather than absolute. Despite the availability of standard methods of measurement, relevant literature has emphasized the comparison of the data with the reference values of any laboratory. However, a method has been offered to standardize laboratory reference values with resource values, which was used in this study. Even different values imply the serum $\mathrm{Zn}$ concentration of the same sample for two different days. Sample preparation for measurement by convenience methods requires fully similar equipment and methods.

The results of some investigations have indicated that the serum $\mathrm{Zn}$ concentration decreases in pregnancy, particularly in the first trimester $(14,22)$. The present study found no association between parity and decreased serum levels, which could be explained by the transient status of $\mathrm{Zn}$ deficiency in this period. In addition, another study in Iran demonstrated that there was no significant association between serum $\mathrm{Zn}$ levels and parity (23). Zn deficiency in pregnant women has been derived to be approximately 95\%. Further, a study in Pakistan reported a $\mathrm{Zn}$ deficiency of $74 \%$ in pregnant women, highlighting the supplement-assisted treatment of such pregnant women. The prevalence of $\mathrm{Zn}$ deficiency in pregnant women in Sudan, Ethiopia, and Vietnam was reported as $38 \%, 53 \%$, and $39 \%$, respectively $(17,24,25)$.

Overall, a higher prevalence of serum $\mathrm{Zn}$ deficiency in women with preterm delivery, compared to term delivery, could be attributed to physiological and metabolic variations and even the acquisition of pregnancy-related infections. Additionally, women with preterm delivery may have lower serum $\mathrm{Zn}$ concentrations at baseline, intensified by physiological decreases in $\mathrm{Zn}$ concentrations during pregnancy. Therefore, serum $\mathrm{Zn}$ concentrations should be monitored since the beginning of pregnancy and the resulting data should be investigated after the completion of pregnancy.

\section{Conclusion}

Although decreases in serum $\mathrm{Zn}$ concentrations could lead to premature rupture of membranes during pregnancy and preterm birth, it could not be regarded as the main parameter in preterm birth. Furthermore, Zn deficiency was highly prevalent in pregnant women. Therefore, nutritional interventions should be performed to prevent complications related to the deficiency of micronutrients including $\mathrm{Zn}$ so that to enhance health maintenance in mothers and children. Accordingly, it is recommended that future investigations evaluate several nutritional factors that are thought to have mutual interaction in order to obtain more robust findings.

\section{Conflict of Interests}

The authors of the present work declare no conflict of interests.

\section{Ethical Approval}

This study was approved by the Ethics Committee of Shahrekord University of Medical Sciences (the ethical code number of IR.SKUMS.REC. 92.3.3) and was recorded by number 1654.

\section{Authors' Contribution}

SS and AK conceived and designed the study. MD acquired the data, and FG and SK analyzed and interpreted the obtained data. In addition, AK, SS, and FF drafted the manuscript. AK, SS, and MF critically revised the manuscript for important intellectual content, and AK supervised and approved the final draft. 
Funding/Support

This work was funded by Shahrekord University of Medical Sciences, Shahrekord, Iran (grant no. 1654).

\section{Acknowledgments}

This work was approved by Shahrekord University of Medical Sciences, Shahrekord, Iran (grant no. 1654). The researchers gratefully thank the patients who participated in this study.

\section{References}

1. Barfield WD. Public health implications of very preterm birth. Clin Perinatol. 2018;45(3):565-77. doi: 10.1016/j. clp.2018.05.007.

2. Newnham JP, Kemp MW, White SW, Arrese CA, Hart RJ, Keelan JA. Applying precision public health to prevent preterm birth. Front Public Health. 2017;5:66. doi: 10.3389/ fpubh.2017.00066.

3. Beck S, Wojdyla D, Say L, Betran AP, Merialdi M, Requejo $\mathrm{JH}$, et al. The worldwide incidence of preterm birth: a systematic review of maternal mortality and morbidity. Bull World Health Organ. 2010;88(1):31-8. doi: 10.2471/ blt.08.062554.

4. Black RE, Allen LH, Bhutta ZA, Caulfield LE, de Onis $\mathrm{M}$, Ezzati $\mathrm{M}$, et al. Maternal and child undernutrition: global and regional exposures and health consequences. Lancet. 2008;371(9608):243-60. doi: 10.1016/s01406736(07)61690-0.

5. Shah R, Mullany LC, Darmstadt GL, Mannan I, Rahman $\mathrm{SM}$, Talukder RR, et al. Incidence and risk factors of preterm birth in a rural Bangladeshi cohort. BMC Pediatr. 2014;14:112. doi: 10.1186/1471-2431-14-112.

6. Alijahan R, Hazrati S, Mirzarahimi M, Pourfarzi F, Ahmadi Hadi P. Prevalence and risk factors associated with preterm birth in Ardabil, Iran. Iran J Reprod Med. 2014;12(1):47-56.

7. Torchin H, Ancel PY. [Epidemiology and risk factors of preterm birth]. J Gynecol Obstet Biol Reprod (Paris). 2016;45(10):1213-30. doi: 10.1016/j.jgyn.2016.09.013.

8. Tellapragada C, Eshwara VK, Bhat P, Acharya S, Kamath A, Bhat S, et al. Risk factors for preterm birth and low birth weight among pregnant Indian women: a hospitalbased prospective study. J Prev Med Public Health. 2016;49(3):165-75. doi: 10.3961/jpmph.16.022.

9. Alijahan R, Hazrati S, Mirzarahimi M, Pourfarzi F, Ahmadi Hadi P. Prevalence and risk factors associated with preterm birth in Ardabil, Iran. Iran J Reprod Med. 2014;12(1):47-56.

10. Lengyel CS, Ehrlich S, Iams JD, Muglia LJ, DeFranco EA. Effect of modifiable risk factors on preterm birth: a population based-cohort. Matern Child Health J. 2017;21(4):777-85. doi: 10.1007/s10995-016-2169-8.

11. Keunen K, van Elburg RM, van Bel F, Benders MJ. Impact of nutrition on brain development and its neuroprotective implications following preterm birth. Pediatr Res. 2015;77(1-2):148-55. doi: 10.1038/pr.2014.171.

12. McGregor JA, Allen KG, Harris MA, Reece M, Wheeler M, French JI, Morrison J. The omega-3 story: Nutritional prevention of preterm birth and other adverse pregnancy outcomes. Obstetrical \& gynecological survey. 2001;56(5):S1-3.doi:10.1097/00006254-200105001-00001.

13. Plum LM, Rink L, Haase H. The essential toxin: impact of zinc on human health. Int J Environ Res Public Health. 2010;7(4):1342-65. doi: 10.3390/ijerph7041342.

14. Khadem N, Mohammadzadeh A, Farhat AS, Valaee L, Khajedaluee M, Parizadeh SM. Relationship between low birth weight neonate and maternal serum zinc concentration. Iran Red Crescent Med J. 2012;14(4):240-4.

15. Nossier SA, Naeim NE, El-Sayed NA, Abu Zeid AA. The effect of zinc supplementation on pregnancy outcomes: a double-blind, randomised controlled trial, Egypt. Br J Nutr. 2015;114(2):274-85. doi: 10.1017/s000711451500166x.

16. Blondel B, Macfarlane A, Gissler M, Breart G, Zeitlin J. Preterm birth and multiple pregnancy in European countries participating in the PERISTAT project. BJOG. 2006;113(5):528-35. doi: 10.1111/j.1471-0528.2006.00923.x.

17. Mohamed AA, Ali AA, Ali NI, Abusalama EH, Elbashir MI, Adam I. Zinc, parity, infection, and severe anemia among pregnant women in Kassla, eastern Sudan. Biol Trace Elem Res. 2011;140(3):284-90. doi: 10.1007/s12011-010-8704-3.

18. Kapil U, Singh P, Pathak P. Serum zinc levels amongst tribal population in a district of Jharkhand State, India: a pilot study. East J Med. 2003;8(2):33-4.

19. Boskabadi H, Maamouri G, Nori M, Mohsenzadeh H, Ayatollahi H, Ghayour-Mobarhan M, et al. Maternal and neonatal serum concentrations of zinc and copper in preterm delivery: an observational study. Trace Elements Electrolytes. 2012;29(4):232-8.

20. Rahmanian M, Sheykhnavaz Jahed F, Yousefi B, Ghorbani R. Maternal serum copper and zinc levels and premature rupture of the foetal membranes. J Pak Med Assoc. 2014;64(7):770-4.

21. Shah D, Sachdev HP. Effect of gestational zinc deficiency on pregnancy outcomes: summary of observation studies and zinc supplementation trials. Br J Nutr. 2001;85 Suppl 2:S101-8. doi: 10.1079/bjn2000301.

22. Aydemir F, Cavdar AO, Söylemez F, Cengiz B. Plasma zinc levels during pregnancy and its relationship to maternal and neonatal characteristics: a longitudinal study. Biol Trace Elem Res. 2003;91(3):193-202. doi: 10.1385/bter:91:3:193.

23. Bahadoran $\mathrm{P}$, Zendehdel $\mathrm{M}$, Movahedian A, Hasan Zahraee R. The relationship between serum zinc level and preeclampsia. Iran J Nurs Midwifery Res. 2010;15(3):120-4.

24. Gebremedhin S, Enquselassie F, Umeta M. Prevalence of prenatal zinc deficiency and its association with sociodemographic, dietary and health care related factors in rural Sidama, Southern Ethiopia: a cross-sectional study. BMC Public Health. 2011;11:898. doi: 10.1186/1471-245811-898.

25. Nguyen VQ, Goto A, Nguyen TV, Vo KT, Ta TM, Nguyen TN, et al. Prevalence and correlates of zinc deficiency in pregnant Vietnamese women in Ho Chi Minh City. Asia Pac J Clin Nutr. 2013;22(4):614-9. doi: 10.6133/ apjen.2013.22.4.05 